\title{
¿Cómo representar la topografía?
}

Técnicas e instrucciones para dibujar diferentes propiedades del relieve Como representar a topografia? Técnicas e instruções para desenhar diferentes propriedades do relevo

How to represent the topography? Techniques and instructions for drawing

different relief properties

Comment représenter la topographie? Techniques et instructions pour dessiner différentes propriétés de relief

\section{Malena Mazzitelli Mastricchio}

\section{(2) OpenEdition}

Journals

Edición electrónica

URL: https://journals.openedition.org/terrabrasilis/2382

DOI: $10.4000 /$ terrabrasilis.2382

ISSN: 2316-7793

\section{Editor}

Rede Brasileira de História da Geografia e Geografia Histórica

Referencia electrónica

Malena Mazzitelli Mastricchio, «¿Cómo representar la topografía?», Terra Brasilis [En línea], 9 | 2017,

Publicado el 30 diciembre 2017, consultado el 05 diciembre 2022. URL: http://

journals.openedition.org/terrabrasilis/2382 ; DOI: https://doi.org/10.4000/terrabrasilis.2382

Este documento fue generado automáticamente el 5 diciembre 2022.

All rights reserved 


\section{¿Cómo representar la topografía?}

Técnicas e instrucciones para dibujar diferentes propiedades del relieve

Como representar a topografia? Técnicas e instruções para desenhar diferentes

propriedades do relevo

How to represent the topography? Techniques and instructions for drawing

different relief properties

Comment représenter la topographie? Techniques et instructions pour dessiner

différentes propriétés de relief

Malena Mazzitelli Mastricchio

\section{La topografía como ciencia y descripción del terreno}

Los manuales de topografía (cómo el libro de Limelette de 1908 o el Compendio de Müller de 1945) suelen describir el levantamiento de manera general, esto es una única manera de relevar. Para estos libros, la topografía no es una manera más de mirar el terreno, sino la única forma posible. Su variación esta solo en función del cambio tecnológico que permite una representación cada vez más precisa del terreno. No hay una ponderación de los elementos que conforman el paisaje topográfico en función de una necesidad en particular del observador. Se releva tal cual es. Una colina será siempre relevada de la misma manera, a partir de la intersección de líneas y planos secantes.

Generalmente, los manuales de topografía luego de definir qué es la topografía se centran en señalar la importancia de la escala de trabajo para realizar el mapa. La selección de la escala está en función del límite de percepción visual. Basándose en que el ojo humano solo puede percibir en el papel hasta $1 \frac{1}{4}$ de milímetros, se determina que la escala adecuada se obtiene a partir del resultado del producto de 0,2 milímetros por el denominador de la escala. A continuación se describen los métodos de levantamiento. El discurso suele ser muy técnico justificando cada paso con una ecuación (cómo la de la pendiente ${ }^{p=\operatorname{tg} a=\frac{z}{d}}$ entre muchas otras). Todas las páginas 
de estos libros suelen estar colmadas de números y gráficos trigonométricos. El levantamiento es el resultado de la aplicación de estas cuentas en donde la percepción del sujeto y su mirada desaparecen.

En la parte de representación del relieve el terreno, propiamente dicho, es clasificado desde "un estudio geométrico (...) asimilándole a una superficie poliedral inscrita, tanto más aproximada a la real del terreno cuento mayor sea el número de caras" (Domínguez García-Tejero, 1968: 466). Asimilar el terreno a una figura geométrica con muchos lados posibles implica que cualquier geoforma puede ser relevada a partir de la aplicación de las fórmulas geométricas.

De hecho de no ser por la descripción del instrumental de levantamiento que fue variando con el tiempo uno podría estudiar las técnicas de relevamiento topográfico con cualquier manual, incluso con uno de principios del siglo XX como el libro de topografía de Limelette de 1908.

4 Sin embargo, a partir de un estudio más detallado sobre los levantamientos topográficos, podemos observar que el saber topográfico tiene un aspecto de oficio, que se adquiría a partir del trabajo cotidiano en las instituciones y de la interacción con sujetos con mayor experiencia que enseñaban un tipo de cultura visual particular. Esta especificidad diluye el carácter universal que los manuales generales de topografía le imprimen a este saber, y permiten pensar a la topografía como una manera de representar el terreno, pero no la única. Veamos algunos ejemplos.

\section{Topografía geológica: el caso de la Dirección de Minas, Geología e Hidrología}

5 En 1953 la Dirección de Minas, Geología e Hidrología (DMGeH) publicó un libro llamado Sugestiones y consejos para jóvenes topógrafos de la Dirección Nacional de Minería, cuyo autor es Orlando Carnacini. Contamos con pocos datos biográficos de Orlando L. Carnacini. Sabemos que reclutaba a los jóvenes con conocimientos en matemática que trabajaban en la Dirección (administrativos, despachante de nafta, etc.), los llevaba de comisión a su casa particular en la provincia de Córdoba y allí los instruía como aprendices. Luego de esta formación, (que consistía básicamente en dibujos, interpretaciones cenitales del terreno y el uso de tablas logarítmicas), los aprendices topógrafos pasaban a trabajar en el Departamento de Topografía fundado en 1912. Quienes se desempeñaban primero como ayudantes para seguir perfeccionando sus conocimientos y luego, cuando adquirían mayor experiencia, podían ser responsables de comisiones en el campo. En cuanto a su producción profesional, Carnacini realizó la topografía de los mapas geológicos elaborados por Augusto Tapia (1893-1966) en 1936, y gran parte de la producción cartográfica de la provincia de Córdoba. Cuando escribió el documento contaba con enorme experiencia en el relevamiento topográfico para la cartografía geológica, y era el jefe del Departamento de Topografía.

El documento no es estrictamente un manual de topografía sino que contiene el "conocimiento práctico adquirido por experiencia propia de muchos años de trabajos en campaña" (Carnacini, 1953: 1).

7 El texto de diecinueve páginas cuenta con siete láminas y dos mapas topográficos que representan el terreno con las curvas de nivel, y tiene como objetivo adelantarse a los problemas que podían presentarse durante la realización del trabajo. Está escrito de 
manera narrativa, y los consejos que presenta son de lo más variados. Están entrelazados con anécdotas personales del autor y de otros topógrafos conocidos por él. La primera parte se dedica cuestiones que tienen que ver con la campaña y el trato con el resto de los integrantes de la comisión.

8 Bajo el subtítulo de "Personal de la comisión y el trato que debe dársele", Carnacini indica que las comisiones debían estar conformadas por un jefe (el topógrafo con más experiencia); un ayudante aprendiz del oficio topográfico; un baqueano que conociera la zona de levantamiento; dos peones contratados a destajo; un cocinero y un chofer con conocimientos de mecánica.

9 Si bien el personal era variado (ayudante, peones, cocinero y chofer), los consejos que da Carnacini son solamente para el trato con los baqueanos. Hay una larga recomendación a los topógrafos para tratar con los hombres de campo, que incluye estar alerta ante sus condiciones "morales y físicas" (Carnacini, 1953: 4). Si bien se reconoce que el " $80 \%$ del buen éxito de la campaña" depende de los baqueanos y peones, hay una gran estigmatización sobre ellos por considerarlos, por ejemplo, supersticiosos y alcohólicos. Por eso se recomendaba a los jefes de la comisión estar provistos de "whisky u otra bebida espirituosa para casos de emergencia", las cuales debían estar bajo llave.

10 Los consejos para el trato con estos hombres son de lo más extenso del libro: se recomienda, para el éxito de la campaña, estimularles su sentimiento de "patriotismo, dedicación e iniciativa" y la importancia de su trabajo.

11 También se advierte, por otro lado, sobre las costumbres culturales y religiosas. Se aconsejaba no contradecirlos, nuevamente estigmatizándolos de supersticiosos. En este punto Carnacini explica en detalle el ritual de la Pachamama que se practica en el norte argentino: incluye términos del dialecto local como "apacheta" (montículo de piedras cuyo tamaño depende del tránsito del lugar, pues cada creyente que pasa deja su propia roca); "acullico" (mezcla de hojas de coca); "llicta" (masa de papa, ceniza y ají muy picante); y "tola" (ramas para hacer una cruz). Para explicar este tema, agrega incluso una lámina en blanco y negro. 
Figura 1: Baqueanos y el rito de la Pachamama

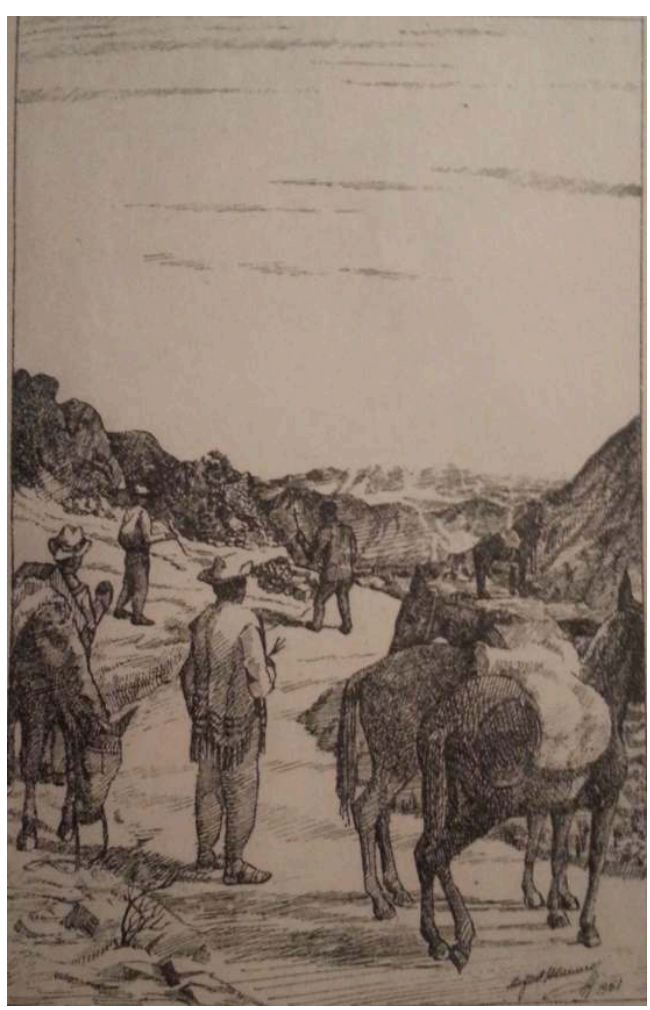

Fuente: Carnacini (1953)

12 En el primer plano de la Lámina se observa a dos hombres desmontados junto a tres caballos, por su vestimenta (sandalias, poncho y sombrero a dos alas) se deduce que no son topógrafos, pues la ropa que Carnacini aconsejaba usar eran sacones, prendas de seda para mantener el calor y sombrero de piel sin visera, a fin de evitar la interferencia con la mirilla del instrumental.

13 En un segundo plano, hay dos hombres realizando la ofrenda sobre la apacheta, construida al costado de un camino. Toda la escena reproduce un paisaje montañoso, las distintas tonalidades de grises se logran a partir del grosor de las líneas (técnica utilizada también para realizar los mapas). El topógrafo, quien dibuja, es el que observa desde afuera. La imagen está firmada por el autor, que no fue Carnacini, su nombre, poco legible, solo aparece en el margen inferior derecho.

Carnacini remarca en el texto otra clase de inconvenientes relacionados con las creencias de los baqueanos. Por ejemplo, que consideran a ciertos cerros como sagrados y por tal razón no aceptan subir a ellos. Como consecuencia, se demoraba el trabajo ya que los topógrafos y sus aprendices tenían que cargar el instrumental hasta la cima. La narrativa oscila, entonces, entre el respeto por las creencias, remarcando la importancia de demostrar cierto interés, que permitirá conseguir la confianza y buena voluntad de las personas, y el trato hacia ellas como portadoras de ingenua religiosidad, sencillez, e ineficacia de los actos.

Según Carnacini, es necesario no hacerlos sentir su "nivel de inferioridad en la cultura general". Para lograr esto, el autor propone promover conversaciones sobre asuntos que ellos conozcan. Tener en cuenta estos consejos evitará que los baqueanos y peones mientan en la información que el topógrafo necesita para realizar el mapa (nombres de cerros, ríos, o lugares adecuados para acampar). 

ya que ellos proporcionaban información valiosa del terreno y les permitían a los topógrafos obtener datos de lugares donde su mirada no alcanzaba. Hasta entonces, en muchas oportunidades los topógrafos se habían guiado por la palabra de los baqueanos, ya sea para registrar topónimos o para saber si una grieta continuaba del otro lado de un cerro. Como aconsejaba Carnacini, el topógrafo debía "informándose por el baquiano (sic) cuáles son los nombres y qué dirección toman al desaparecer de su vista por interposición de los cerros, lo que se anotará a continuación del final del trazo y siguiendo la dirección" (Carnacini, 1953: 15). Sin ellos la tarea resultaba casi imposible, no solo porque ayudaban a visibilizar lo que no siempre observaba el topógrafo, sino también porque, en el pasado, el conocimiento que tenían del terreno permitía a este, muchas veces, sobrevivir en el campo.

A continuación, el instructivo mencionaba detalladamente los lugares más convenientes para ubicar el campamento, teniendo en cuenta la existencia de zonas potencialmente inundables, cercanas a meandros o junto al río; zonas expuestas a incendios o áreas en las que existe el peligro de enfrentarse con animales ponzoñosos (víboras, arañas, garrapatas, etc.). Luego de agregar instrucciones sobre la forma más correcta de cruzar un río caudaloso, comienzan las descripciones de carácter técnico, orientadas a la práctica en sí.

19 En una segunda parte, y luego de describir estas cuestiones relacionadas con el trabajo de campo que hacen a la labor del topógrafo de la Dirección de Minas Geología e Hidrología, Carnacini propone "pasar ahora a concretar cómo debe desenvolverse un topógrafo que se especializa en levantamientos destinados a estudios geológicos mineros e hidrológicos" (Carnacini, 1953: 13), no dejando duda alguna sobre la especificidad del trabajo.

El relato parece incluir en este segmento a otro interlocutor, ya que no se trata solo de consejos para jóvenes topógrafos sin experiencia de campo, también está destinado a topógrafos sin experiencia en relevamientos específicos para elaborar mapas geológicos. En el apartado "Otras indicaciones de carácter general”, después de dar instrucciones sobre la toma de decisiones ante problemas climáticos (como tormentas, nieve o vientos), Carnacini incluye consejos para realizar levantamientos topográficos específicos para los estudios geológicos y minero, no cualquier levantamiento. 
La cita deja entrever que está dirigida a topógrafos acostumbrados a relevar espacios de menores dimensiones que los ámbitos relevados para construir una hoja topográfica de la Dirección. Estas cubrían una extensión territorial de 30' de latitud por $45^{\prime}$ de longitud; las medidas del terreno eran de aproximadamente $55,5 \mathrm{~km}$ por $83,25 \mathrm{~km}$.

Una vez que el topógrafo encontraba el cerro más alto, que le permitía la mejor vista panorámica del paisaje, debía orientar el teodolito a $0^{\circ}$ con el norte magnético. Esto hacía más sencillo ubicar luego el punto medido en el plano. Sin embargo, también era útil porque si se producía una perturbación o desorientación de la aguja, por ejemplo en el caso de existir en la zona formaciones metalíferas (como magnetitas), se iba a poder informar con mayor exactitud a los geólogos e ingenieros en minas. Una vez ubicado el aparato, y comenzada la edición por parte del aprendiz, Carnacini aconsejaba al topógrafo realizar un croquis cenital, como el mapa topográfico. El relieve debía representarse a partir de curvas de nivel, aumentando la frecuencia en zonas de pendiente elevada y disminuyendo la cantidad en áreas de relieve suave. Se aconsejaba representar las zonas del relieve con pendientes escarpadas por medio de achurados. Una vez terminada la medición, el jefe debía revisar todos los cálculos y chequear que los cerros del croquis hubiesen sido medidos correctamente por el ayudante. Como veremos el tipo de mapa militar de campaña era diferente.

La figura 2 muestra la blick ${ }^{1}$ que se debía realizar en el campo y que remplazaba la exploración previa. Esta era dibujada desde una única estación, sobre un cerro elevado (el cual tambien visibiliza a partir de un dibujo), y era de carácter general, esto es una blick que "abarque toda la extensión a su vista y detallendo todo lo que este a su alcanse dentro de tres a cinco kilometros" (Carnacini, 1953: 13). La infomación que se vuelca en el mapa, nombre de los cerros y ríos, era otorgada por el baqueano quien "no se movera [del lado del topógrafo] y estará atento a su trabajo, transmitiendole todo los detalles de importancia." (Carnacini, 1953: 13). En base a este realizará la campaña y el mapa topografico. 


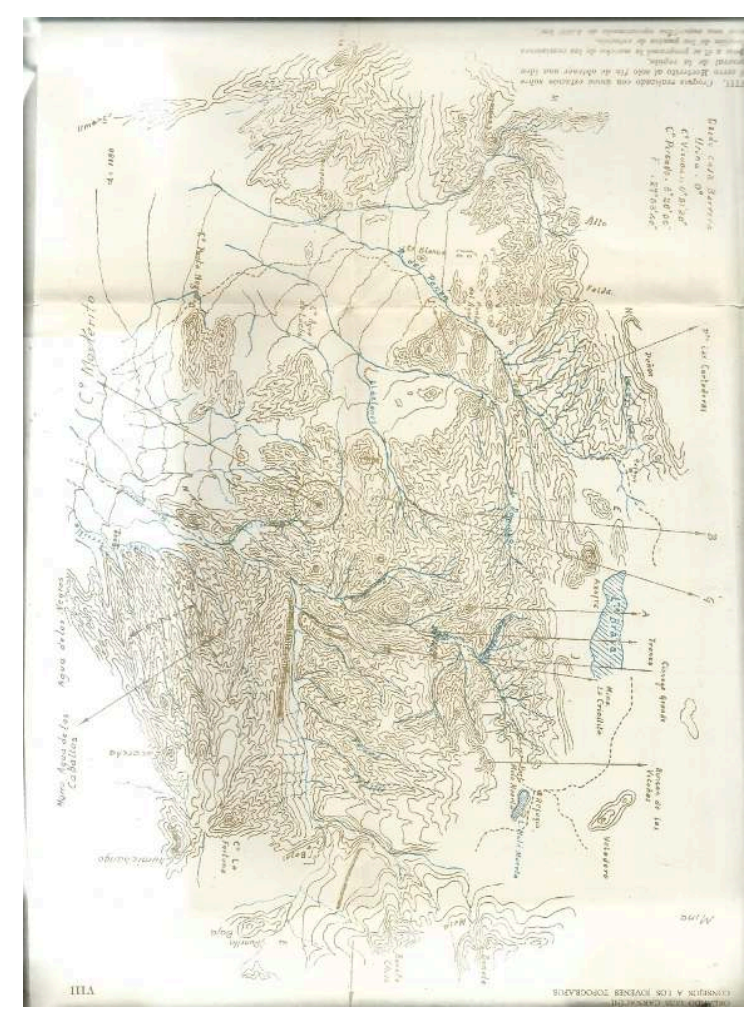

Fuente: Carnacini (1953)

Durante el levantamiento el topógrafo debía siempre tener presente y no olvidar "en ningún momento cual es la finalidad del estudio que está realizando" (Carnacini, 1953: 14). En este sentido sugería ponderar elementos por sobre otros y aconseja a los topógrafos no seguir en todos los casos la ley de la escala como se enseña en los manuales de topografía, ya que hay detalles que son insignificantes a los ojos de un topógrafo común, pero para la mirada geológica adquieren relevancia. De manera tal que un topógrafo especializado en el levantamiento de topografía para geología debía priorizar el detalle. También debían tenerse en cuenta los cambios bruscos en la formación y color de las rocas que se representaban porque podría indicar presencia de minerales, y esto era de gran importancia para los ingenieros en minas, otras de las especialidades de la Dirección.

La especificidad de la topografía se aprendía con la práctica del relevamiento en la institución.

Carnacini muestra un tipo de topografía orientada para quien la va a usar, no es cualquier topografía. Incluso aconseja que los topógrafos que se "especialicen en esta clase de levantamientos adquieran algunos conocimientos elementales de geología y minería" (Carnacini, 1953: 14. Los destacados son nuestros). La recomendación se extiende para el personal de gabinete, es decir a los cartógrafos encargados del dibujo de las cartas topográficas.

Otro apartado al cual Carnacini dedica tiempo y detalles se refiere al manejo de los animales. Bajo el apartado "Precauciones a tomar para contar con buena tropa durante toda la campaña" y con una estrategia similar a la sugerida para el trato con los baqueanos, el autor aconseja sobre el mejor modo de tratar a los animales: cómo cuidarlos, atenderlos y no castigarlos. Luego de una larga descripción, en la que explica 
hasta cómo y cuándo darles de comer, cómo cargar el material, lo necesario de darles tiempo para descansar (resuello) y para orinar, Carnacini alerta sobre los peligros que corre el jinete si no se siguen sus sugerencias e incluye una lámina que muestra gráficamente cómo debe colocarse la carga para que animal no derrape en caminos de cornisa.

Carnacini describe a los elementos de la campaña: hombres, instrumental y animales en el mismo tono. Destaca en más de una oportunidad que sus indicaciones son producto de "observaciones personales de campaña" (Carnacini, 1953: 10).

El documento analizado pone de relieve, a nuestro entender, la importancia dada a la experiencia como base para adquirir y para transmitir los conocimientos topográficos. El texto finaliza con consejos para relevar caminos, y con una tabla en la que constan cuáles son las estaciones del año más propicias para salir al campo, según la región del país de la que se trate.

\section{Topografía militar: las recomendaciones del Instituto Geográfico Militar}

31 El Instituto Geográfico Militar (1904-2009) estuvo encargado de realizar la cartografía civil de la Argentina desde 1912, año en el cual presentó un plan sistemático de relevamiento a diferentes escalas. A la cartografía para usos civiles se le había destinado la escala 1:100.000. No obstante además de esta cartografía civil, el Instituto realizaba otro tipo de cartografía topográfica, destinada a fines exclusivamente militares. Esta es la topografía para artillería.

Podemos dividir en dos los libros usados para este trabajo. Por un lado los libros que están escritos de puño y letra por un autor como el libro de 1928 Nociones elementales de dibujo panorámico y fotografía editado por la Biblioteca del Suboficial; por el otro los libros cuya autoría es la misma institución militar. Estos son el libro Reglamento de Topografía para artillería de 1958 y el libro Topografía para artillería de 1969 ambos editados por el Ejército Argentino en los talles del Instituto Geográfico Militar.

A pesar de estas diferencias en los libros de topografía con fines militares no hacen referencia al trabajo de con baqueanos, como sí hace Carnacini. Esta diferencia puede explicarse porque en la topografía para artillería las comisiones son muchas más numerosas y la terea que se encargaban los baqueanos contratados por la Dirección en este caso era realizada por los soldados de menor rango, llamados generalmente "subordinados".

La falta de baqueanos no nos impide encontrar una especificación en la manera de relevar y mirar el terreno. Por ejemplo en el libro de 1928 Nociones elementales... luego de dar nociones básica de cómo realizar una blicks (Mazzitelli Mastricchio, 2017), se dedica a dar instrucciones sobre el dibujo militar propiamente dicho. En palabras del mismo autor: "para que [dicha blicks] tenga utilidad militar, es necesario agregarle una serie de leyendas en la cuales el que lo recibe pueda orientarse sobre el terreno y servirse de él como si estuviera en el mismo" (Mile, 1928: 63). Los nombres a los que se refiere el autor son topónimos que hace referencia a las posibilidades de movilidad de la tropa. En la figura 3 se observa los detalles a los cuales se debía prestar atención en la topografía militar: por un lado observamos que se destacan las vías de comunicación y las distancias que hay entre el observador y los algunos puntos específicos, en este caso 
"villa Chacabuco (3600m)" al "camino de Est. Piedras (8km)" del ferrocarril y a la "Estancia M (4000 m)". También se visibilizan los lugares parar las trincheras o la "presunta posición de la artillería".

Figura 3: Croquis o blick militar

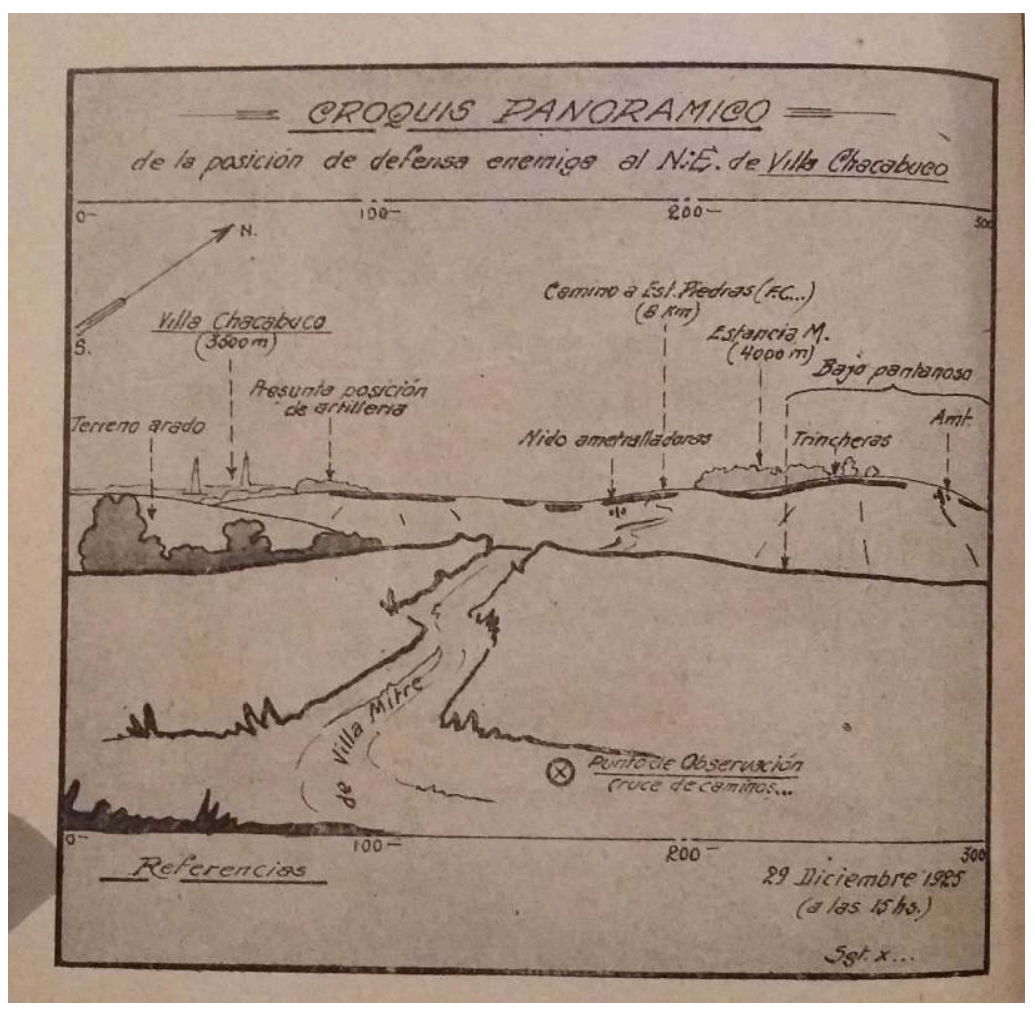

Fuente: Mile 1928

La ubicación y la importancia de la planimetría es mucho más ponderable que el caso de Carnacini. En otra publicación (de la cual no constamos con datos de edición formales pues son apuntes que se repartían entre los topógrafos del Instituto Geográfico Militar) también se ponderan los detalles planimétricos como importantes para la topografía porque estos elementos "permitirán que se reconozca un terreno o zona del mismo, sin haber estado personalmente en él" (Apuntes S/d: 8). El mapa topográfico militar debía ayudar a crear una imagen del terreno e imaginar cómo sería sin haber estado ahí. Una especie de imagen mental del terreno sin cuerpo y sin presencia física (Malosetti, 2005: 1), un paisaje topográfico imaginado (Mazzitelli Mastricchio, 2016).

Los topógrafos militares observaban y representaban al relieve en función del desplazamiento y movimiento de la tropa. Reconocen que la topografía tiene dos partes: la representación de la altimetría y de la planimetría, sin embargo, las alturas y al ubicación del relieve está en función del movimiento estratégico, lo que interesa de un cerro es su ubicación y sus dimensiones del mismo modo que interesa una estación de tren o el edificio de una estancia. Los elementos representados (relievo o no) están ahí para el mismo fin, solo saber su ubicación. Conocer donde están ubicados los obstáculos planímetricos o altimétricos permitiría calcular las marchas de los soldados, los tiros directos e indirectos y conocer las defensas naturales y la realización de fortificaciones (Apuntes, s/d, 10). 
La topografía que mira el topógrafo de la Dirección de Minas es diferente: representar el terreno, su forma y su color es imprescindible para el trabajo geológico. Esto no sucede en la cartografía militar en donde conocer el color de la roca es totalmente ajeno a los intereses de la milicia. En la topografía militar conocer las dimensiones de los objetos y su distancia es primordial. Por eso no recomiendan realizar una alteración de la escala para visualizar detalles de la roca.

Si analizamos el Reglamento de Topografía para artillería publicado por el IGM en 1958 vemos que incluso las decisiones que se toman están en función del tiempo y del imprevisto de la batalla. El libro está destinado enteramente a militares oficiales y suboficiales con conocimientos en: aritmética, geometría, algebra, trigonometría plana y esférica, cosmología y geodesia y conocer los principios del funcionamiento de los aparatos ópticos reglamentarios y del instrumental de relevamiento (IGM, 1958: 2). Evidentemente el libro está orientado a topógrafos militares formados. No es un manual de topografía sino que reglamenta la especificidad del trabajo topográfico militar en el campo. Incluso los trabajos topográficos parecen ser efímeros. Solo sirven en momentos de guerra.

Incluso si la medición debía hacerse a partir de una poligonal (abierta o cerrada) o con una triangulación se determinaba en el momento por el oficial topógrafo encargado dependiendo, entre otras cosas, de la posición de la tropa enemiga y del tiempo con que contaban. El número de puntos tomados para realizar el relleno del mapa, esto es la cantidad de estaciones realizada con el instrumental dependía también del tiempo que se tuviera y de la cantidad de soldados disponibles.

En la figura 4 vemos un plano topográfico publicado en Topografía para artillería de 1969. El mapa muestra los trabajos topográficos llevados a adelante por los topógrafos militares para la "Adquisición de Blancos". La Figura 5 muestra el recorrido de los tres grupos militares encargados de la medición. Ambas representan los objetos relacionados con la medición: las estaciones, los puntos ópticos, las posiciones de los grupos y el desplazamiento de la tropa. En las imágenes se observan pocos elementos del relieve propiamente dicho como curvas de nivel. La representación del terreno aparece solo como una línea achurada como en la figura 4 y ondulada en la figura 5.

Esta manera de representar el terreno era enseñada en la institución militar a los topógrafos que formaban parte de la fuerza de artillería. Se les enseñaba una manera particular de mirar el territorio. Para recibir esta formación los estudiantes ya contaban con conocimientos en el arte de la topografía. Lo que adquirían con esta formación era un manera particular de mirar. 
Figura 4: Mapa topografico para artillería

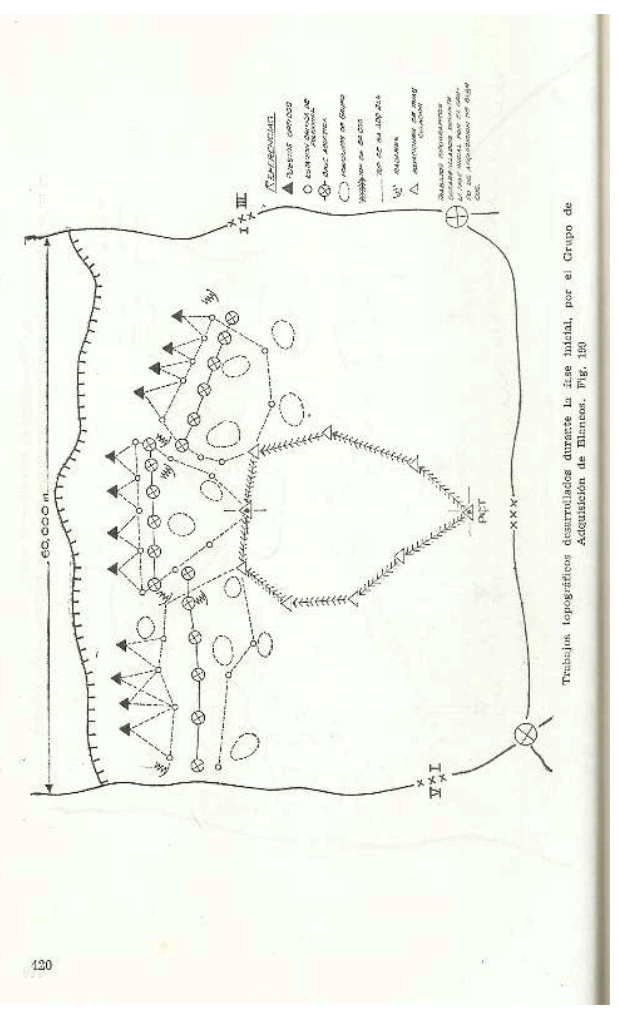

Fuente: Ejército Argentino, 1969

Figura 5. Mapa topografico para artillería

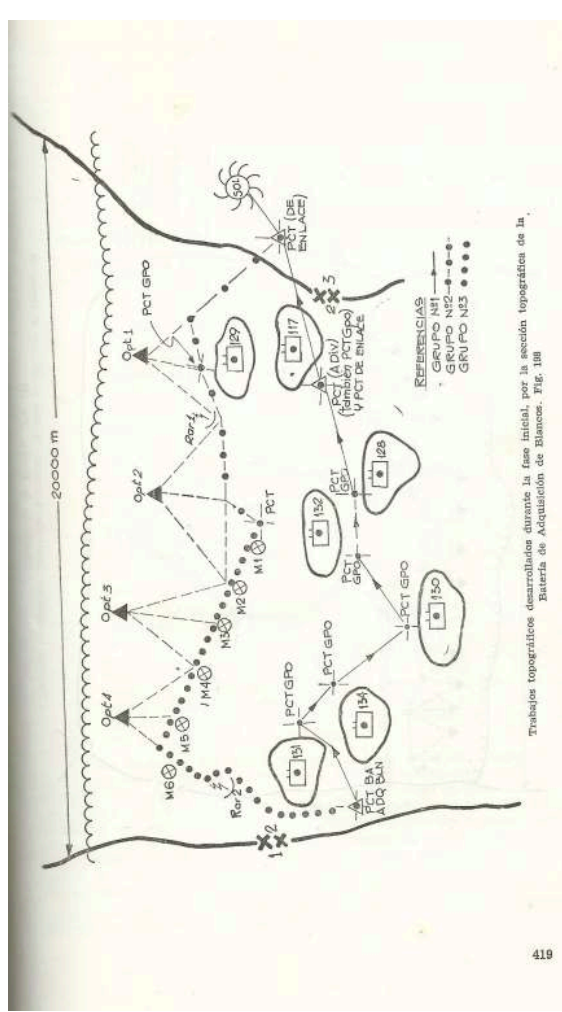

Fuente: Ejército Argentino, 1969 


\section{Conclusión}

A lo largo del trabajo demostramos que la representación topografica del terreno no es universal como generalmente es planteado en los manuales de topografía. Lejeos de eso, la representación topografica del terreno varía según los objetivos para los cual el mapa fue pensado: si el mapa topografico estaba confeccionado con fines geologicos, la manera de volver visible el terreno sería ponderando siertas formas y colores de la roca, incluso se permiten siertas 'licencias topográficas' como la alteración de la regla de la escala. Mientra que cuando el fin del mapa era para usos militaes, otros eran los elementos que adquirian importacia y que tienen que ver con el desplazamieno de la tropa. Aquí la planimetría y la altimetría tienen la misma función, la de ser obstaculos para la topilla militar o para adaptarlos como refujio para la defensa.

Esta epecificidad de la topografía se adquiría en los lugares de trabajo, en donde se impartía una especie de cultura visual topografica de cada intitución. La particularidades topográficas de las instituciones se impartían en el trabajo cotidiano, con otros topografos con mayor formación -lo que imprimia un cierto caracter de oficio-; pero tambien con la publicación de diferentes instructivos (o consejos) que marcaban el quehacer de los topografos y que le indicaban como mirar.

\section{BIBLIOGRAFÍA}

Carnacini, Orlando (1953). Sugestiones y consejos para los Jóvenes Topógrafos de la Dirección de Nacional de Minas, $\mathrm{N}^{\circ} 135$, DNM, Buenos Aires, [28pp].

Ejército Argentino. (1969). Topografía para Artillería. Tomo I, Instituto Geográfico Militar, Buenos Aires.

Favelukes, Graciela (2011). "Miradas atentas, dibujos precisos, territorios esquivos”, en Actas de Las I Jornadas de Visualidad y Espacio: Imágenes y Narrativas, UADER, Paraná, Entre Ríos. ISBN: 978-987-23846-8-5.

Garcia Tejedo (1968). Topografía General y Aplicada, Editorial Dossat S.A., Madrid.

MALOSETTI, Laura (2005). “ ¿Una imagen vale más que mil palabras? Una introducción a la lectura de las imágenes” posgrado virtual identidades y pedagogía. Aportes de la imagen para trabajar la diversidad en la educación, Buenos Aires, FLACSO/Argentina.

Mazzitelli Mastricchio, Malena (2017). El uso de vistas, bosquejos, notas, fotografías y otros insumos visuales para la traducción de información topográfica en la cartografía topográfica de la Dirección Nacional de Minas, Geología e Hidrología. Tesis Doctoral, Facultad de Filosofía y letras de la Universidad de Buenos Aires.

Mazzitelli Mastricchio, Malena (2016). Los paisajes topográficos ocultos en los mapas. El caso de Godoy Bonnet en la Dirección De Minas, Geología E Hidrología. Geograficando, 12 (1), e005. Recuperado de http://www.geograficando.fahce.unlp.edu.ar/article/view/Geov12n01a05 
Mile (1925). Nociones elementales de dibujo panorámico y fotografía, Biblioteca del suboficial, Círculo Militar, Buenos Aires.

Ministerio de Guerra (1958). Reglamento de Topografía para la Artillería, Instituto Geográfico Militar, Buenos Aires.

\section{NOTAS}

1. Para diferenciarnos de las definiciones más tradicionales del concepto de vista, en la tesis utilizaremos el vocablo en alemán blick; que según el Science Dictionary German- English (1946), quiere decir "vista". El término era usado por topógrafos alemanes que trabajaron en la Dirección Nacional de Minas, Geología e Hidrología, como Pablo Schewzer, quien en sus libretas de campo por ejemplo, anotaba en el margen de la hoja la sigla $B L$ y un número que identificaba cada una de estas imágenes en el terreno. Es en este contexto que utilizamos al concepto de blick para identificar todos aquellos apuntes manuscritos que dibujaban el paisaje topográfico, en cualquier formato (papel, libreta, cuaderno), que los topógrafos elaboraban durante el trabajo de campo.

\section{RESÚMENES}

La topografía abarca dos aspectos del relevamiento del terreno: la planimetría y la altimetría. Mientras que la planimetría cambia más rápidamente debido a la acción humana (el trazado de nuevas rutas, caminos, el crecimiento de los pueblos o la construcción de diques etc.), la altimetría es más constante (los cambios surgen de la variación de los instrumentos de medición y no de variaciones reales en la altura del relieve). Para demostrar que la cartografía topográfica puede ser más específica en la planimetría que en la altimetría (y viceversa) según quién produzca y consuma tales mapas, analizaremos las publicaciones utilizadas para instruir a los topógrafos como parte de la formación de militares del Instituto Geográfico Militar y otra realizada por la Dirección Nacional de Minas Geología e Hidrología.

A topografia abrange dois aspectos do levantamento do terreno: planimetria e altimetria. Enquanto a planimetria muda mais rapidamente devido à ação humana (traçado de novos roteiros, estradas, crescimento de povoados ou construção de barragens etc.), a altimetria é mais constante (as mudanças decorrem da variação dos instrumentos de medida e não de variações reais na altura do relevo). Para demonstrar que a cartografia topográfica pode ser mais específica na planimetria do que na altimetria (e vice-versa), de acordo com quem produz e consome tais mapas, analisaremos as publicações usadas para instruir os topógrafos como parte de seu treinamento no Instituto Geográfico Militar e na Direção Nacional de Minas, Geologia e Hidrologia.

The topography covers two aspects of terrain survey: planimetry and altimetry. While planimetry changes more rapidly due to human action (tracing of new routes, roads, the growth of villages or the construction of dikes etc.), the altimetry is more constant (changes arise from the variation of the instruments of measurement and not of real variations in the height of the relief). To demonstrate that topographic mapping may be more specific in planimetry than in altimetry (and vice versa) according to who produces and consumes such maps, we will analyze 
the publications used to instruct surveyors as part of the military training of the Military Geographic Institute and another carried out by the National Bureau of Mining Geology and Hydrology.

La topographie couvre deux aspects de l'étude du terrain: planimétrie et altimétrie. Alors que la planimétrie change plus rapidement en raison de l'action humaine (traçage de nouvelles routes, routes, croissance des villages ou construction de digues, etc.), l'altimétrie est plus constante (les changements résultent de la variation des instruments de mesure et non de variations réelles de la hauteur du relief). Pour démontrer que la cartographie topographique peut être plus spécifique dans la planimétrie que dans l'altimétrie (et vice versa) selon qui produit et consomme de telles cartes, nous analyserons les publications utilisées pour instruire les géométres dans le cadre de la formation militaire de l'Institut géologique militaire et une autre réalisée par la Direction nationale de la géologie minière et de l'hydrologie.

\section{ÍNDICE}

Keywords: topography, planimetry, altimetry, Military Geographic Institute, National Bureau of Mining, Geology and Hydrology

Palabras claves: topografía, planimetría, altimetría, Instituto Geográfico Militar, Dirección Nacional de Minas, Geología e Hidrología

Palavras-chave: topografia, planimetria, altimetria, Instituto Geográfico Militar, Direção Nacional de Minas, Geologia e Hidrologia

Mots-clés: topographie, planimétrie, altimétrie, Institut géographique militaire, Direction nationale de minière, géologie et hydrologie

\section{AUTOR}

\section{MALENA MAZZITELLI MASTRICCHIO}

Becária postdoctoral del CONICET; Universidad Nacional de Entre Ríos; Universidad de La Plata 